\title{
Traversing State, Agribusinesses, and Farmers' Land Discourse in Kenyan Commercial Intensive Agriculture
}

\author{
Peter Narh
}

\begin{abstract}
From a qualitative study of sugarcane production in Chemelil (western Kenya) and insights drawn from the Kenyan land reform enacted in 2012, this study contends that the goal of land reform to provide farmers with certainty of rights to land to invest in and benefit from agriculture is heavily weakened by the farmers' lack of control over agricultural inputs. Land reform and intensive agriculture, such as sugarcane production, share the same market-based land discourse, where land is considered an environmental asset to be harnessed efficiently for high productivity. Although this discourse supports the application of high inputs for maximum agricultural outputs, it has also eroded farmers' power and control over their lands. This loss of power and control occurs through the supply of high-cost agricultural inputs from external sources, such as state research agencies and the Chemelil Sugar Company. The control of inputs by sources external to farmers stifles possible farmbased innovations that could reduce farming costs. The chapter, thus, contends that, although land reform aims at farmers' utmost benefit from land, the farmer's lack of control over agricultural inputs limits the benefits they derive from land use for intensive agriculture; this is especially true in the case of small-scale farmers.
\end{abstract}

Keywords Land discourse $\cdot$ Intensification $\cdot$ Power $\cdot$ Control

\section{Introduction}

In this work, a political ecology approach is employed to discuss the ways in which efficient land use and land productivity principles connect state-supported land reform, agribusinesses, and sugarcane farmers in Kenya, along with the outcomes of this connection for the control of these farmers over their lands. In particular, this study uses a high land use productivity principle to connect the Kenyan land reform enacted in 2012 with intensive sugarcane production in Chemelil in western Kenya, probes how the discourses around this principle distribute power and control

P. Narh (凶)

Institute of African Studies, University of Ghana, Legon, Ghana

e-mail: PNarh@ug.edu.gh 
over sugarcane farmlands, and discusses its implications for farmers. According to Manji (2006), land reform denotes the process and associated actions of the enactment, enforcement, and evaluation of land policies and legislation by which land rights relations among people are restructured or reorganised. From the 1970s, the World Bank provided credence for land reform, noting that land reform is necessary to meet the growing food needs and enhance agricultural productivity in general (World Bank 1975). The Bank asserted that reorganisation of land rights would provide more equitable access, improve land productivity, and broaden the distribution of benefits.

Focusing on sugarcane production in Kenya, the claim of this study is that, despite the long history of land reform in Kenya, which aims to clarify and strengthen the tenure and control of farmers over their lands and improve agricultural productivity, smallholder farmers in Kenya have lost significant control over their lands. The weakened control is a result of power imbalance between farmers and agribusinesses, leading to a gradual loss of land over time within farming households. Currently, the goal of land reform to ensure efficiency in land use for higher productivity, especially in agriculture, does not address how agricultural inputs generate power over land and constrain farmers' innovation to create infrastructure to sustain their lands. Land sustainability infrastructure in this context includes purposefully established institutional and physical structures of any sort that have the ability to motivate farmers as a collective to learn from each other. Additionally, this infrastructure will empower farmers to negotiate with agribusinesses and the state over land inputs and thus benefit more from their lands. Land reforms and agricultural development are currently positivist in nature and process in a way that neglects other outcomes of inputs besides productivity, such as political control over land.

In this study, the goal is to contribute to scientific evidence suggesting that land reform and its linkage with agricultural productivity in Africa should transcend beyond market-led, positivist outcomes of efficiency and high productivity of land to one that considers the role of agricultural productivity processes in the development of power and control over farmers' lands over time. Land reforms are usually couched at the national level and, although they are directly linked to agricultural development that occurs at the sub-national level, hardly reach down to identify and incorporate local outcomes that can improve the reforms and agricultural development to benefit local contexts. In a country where agriculture, particularly intensive cash crop farming such as production of sugarcane, contributes about $22 \%$ to the gross domestic income (Kenya Economic Update 2019), ${ }^{1}$ understanding that land is the primary assets of farmers, analysing how land reform and agricultural intensification connect with farmers' control over their lands have significant implications for the sustainability of land, agricultural development, and livelihoods currently and in the future.

The linkage between land reform, agricultural productivity, and farmers' control over their lands is relevant because agriculture forms the basis of the economies of

\footnotetext{
1 https://documents.worldbank.org/en/publication/documents-reports/documentdetail/820861554 470832579/kenya-economic-update-unbundling-the-slack-in-private-sector-investment-transform ing-agriculture-sector-productivity-and-linkages-to-poverty-reduction.
} 
most African countries. To this end, in Africa, the land productivity principle has driven intensified agriculture into a dominant paradigm that has gained prominence over the last decades, with implications for national transformation (Loconto et al. 2020). In Africa, harnessing agricultural land in a highly intensive manner has been partly programmed through land tenure reforms. Unfortunately, land reforms and their attendant agricultural productivity goals are poorly foregrounded in the evolving social and political outcomes for farmers, produced by these same reforms. The outcomes of land reform and the land productivity discourse significantly determine the sustainability of land and agriculture in local contexts; however, this remains oblivious to policymakers and agricultural managers. Considering and emphasising the local land discourse in land reform and agricultural development in a reflexive process will provide a better sense of ownership, control over land, and profitable investments for farmers (Place 2009). In this study, these issues are analysed through different perspectives, beginning with a broad perspective on Africa.

\section{Land Reform's Linkage with Agricultural Productivity}

Lipton (2009) confirms that land reform is about instituting 'laws with the main aim of reducing poverty by substantially increasing the proportion of farmland controlled by the poor, and thereby their income, power, or status'. In this statement, control over land by farmers is a key goal that ought to play a significant role in shaping land reform. In the context of rural areas, the aim of land reform is to enhance agricultural productivity and reduce poverty among people. Through increased security of tenure, the theory is that land reform provides motivation for farmers to increase investments in land, thus, harnessing land resources more effectively. Although the contexts vary, the theory underpinning land reform in Africa is that efficiency in land use can raise the productivity of land to meet the needs of growing populations (World Bank 1975). Secure land tenure is processed through the registration of land titles following a market approach that makes land a commodity to be exchanged. The notion that the formal land titling and individualisation of land rights in developing countries leads to higher investments in land and agricultural productivity prevails in academic and development practice circles (Narh et al. 2015). In 1975, the World Bank gave credence to the economic principles of efficiency and productivity that underlie land reforms. However, land tenure reforms in pursuance of market-based productivity weaken farmers' control over what they produce and how they produce; thus, this tenure places control over land and land inputs in the hands of external forces (Obeng-Odoom 2012) and erodes farmers' control over land.

In Africa, each country's peculiar condition has directed the approach adopted for land reform (Netshipale et al. 2020). On the whole, liberal market-led approaches are used in most land reform programmes in Africa (Netshipale et al. 2020). The general trend is the direct linkage between land reform and agriculture; this has enabled land reform policy to support the provisioning of institutional and technological capital to promote agricultural development and intensification grounded in biotechnologies 
and agricultural infrastructure, such as irrigation schemes, marketing cooperatives, and crop research facilities, among others. These technologies and infrastructure undoubtedly improve farmers' capital stock (Netshipale et al. 2020). In the same vein, Tenaw et al. (2009) showed from their research that investments in agricultural technologies and ameliorating climatic conditions are the predominant issues for agriculture in most of Africa. Gottlieb and Grobovšek (2019) also found a direct link between land reform and agricultural development, highlighting that land reform addresses the agricultural investment challenges associated with communal land tenure that is said to inhibit productivity. Logically, this implies that land reform that formally diminishes customary laws over land would almost always create conditions for investments in agricultural productivity. With regard to Zimbabwe, Zikhali (2008) confirms that land reforms enhance the land productivity of poor households through the enhanced use of agricultural inputs, such as fertilisers, by households whose land tenure is governed by the reforms. Nonetheless, deduced from the field data for this work, what is missing in land reform and agricultural development is the conditions that would encourage farmers to collectively innovate local technologies and infrastructure that can complement supplied inputs. The essence of this process is to reduce power imbalances between farmers and managers of current input knowledge and technologies, such as agribusinesses.

Fuglie and Rada (2013) explained the status of agricultural research that, although still low, land tenure reforms and agricultural research investments are increasing and driving farm productivity in Africa. Therefore, the objectives of land reforms in Africa have been to increase the productivity of land through the efficient use of high inputs externally supplied to farmers (Fuglie and Rada 2013). Since the 1990s, agricultural output in Africa south of the Sahara has risen significantly through land reforms and investments in agricultural technologies rather than expansion into new lands (Fuglie and Rada 2013). Although it is contentious whether vacant lands still exist in most rural areas, agricultural technologies have transformed agriculture and reduced pressure on land to produce more. However, this has not been without power struggles between farmers and agribusinesses.

In the discussions on land reform and agricultural productivity, control for farmers (over land) is assumed to be achieved through security and clarification of land rights. Field research for this study shows that assuming control over land under the weight of land tenure security and certification of land rights does not bring into effect the recognition of the full impact of land reform on power production at the farm level. The result of power imbalances at the farm level is that innovation by farmers is stifled, which ironically erodes any gains made in agricultural development. This is explained in our study, with empirical evidence provided in the section 'Results and Discussion'. Boone (2019) observed that land reform and agricultural productivity approaches have centred on a 'one principle fits all' process, but this is not necessarily good. Factors that significantly impact the outcomes of land reform and agricultural productivity vary under different ecological and human conditions, including landbased power production (Gollin et al. 2014). Based on the empirical data, this study contends that the utility of reforms and attendant agricultural productivity for local 
people depends to a great extent on how farmers are able to exert control over agricultural technologies and infrastructure.

Perhaps, it is crucial for land reform to consider Place's (2009) finding that in Africa, the link between land tenure reforms for agricultural productivity is not a direct one that only involves promoting investments in land. Rather, the link should vary depending on a myriad of factors from community to community. Place (2009) suggested that policy responses to agricultural challenges must consider the microlocal context of targets of agricultural development, as well as how overarching macro and sectoral conditions influence the local contexts. In Africa, where land reform has been implemented, the goal of reforms for agriculture has been reduced to market principles of economic efficiency and increased productivity (Obeng-Odoom 2012). These principles have been oblivious to the effect of power (produced through control over agricultural inputs and processes) on farmers' innovations towards land sustainability and agricultural productivity. Although their land tenure may be secure, the prominent power inherent in agricultural technologies and infrastructure can weaken the control of farmers over their lands and, thus, reduce the benefits they derive from such lands. The high influence of power inherent in agricultural technologies and infrastructure beyond the control of farmers can pose high transaction costs for farmers, tie them to exploitative modes of agriculture, and inhibit their innovative power crucial for sustainable livelihoods. Narh et al. (2015), in accord with Place (2009), also call for land reforms to be reprogrammed from time to time in their local contexts to incorporate factors that affect benefits from land for all stakeholders. In this respect, a national-level land reform should possess the flexibility to be reformulated at sub-national levels for inducing sustainable positive effects on local livelihoods.

\section{Methods}

The data for this study are drawn from a larger dataset obtained through empirical field research conducted since 2018 in sugarcane growing communities in and around Chemelil in the Nyanza region of Kenya and Mumias in western Kenya. However, this study focuses on the Chemelil sugarcane growing belt. Chemelil was chosen for this study as part of a wider study on the implications of land reform for agricultural intensification and land sustainability in Kenya. The Chemelil sugarcane growing zone was chosen owing to the relatively less complicated access to the Chemelil Sugar Company (Fig. 1), made possible by previous contacts that the author made with officials of the company. Moreover, the Chemelil sugarcane industry is situated within a competitive zone of cane millers in Kisumu City and Muhoroni Town, which could influence its relationship with farmers. Unlike many of the cane mills in Kenya, the Chemelil Sugar Company was still functional as of October 2020.

The Chemelil Sugar Company has a history of suspension and resumption of operations, due to low returns on purchased cane. Chemelil is one of the largest sugarcane growing belts in Kenya. The suspension and resumption in operation 


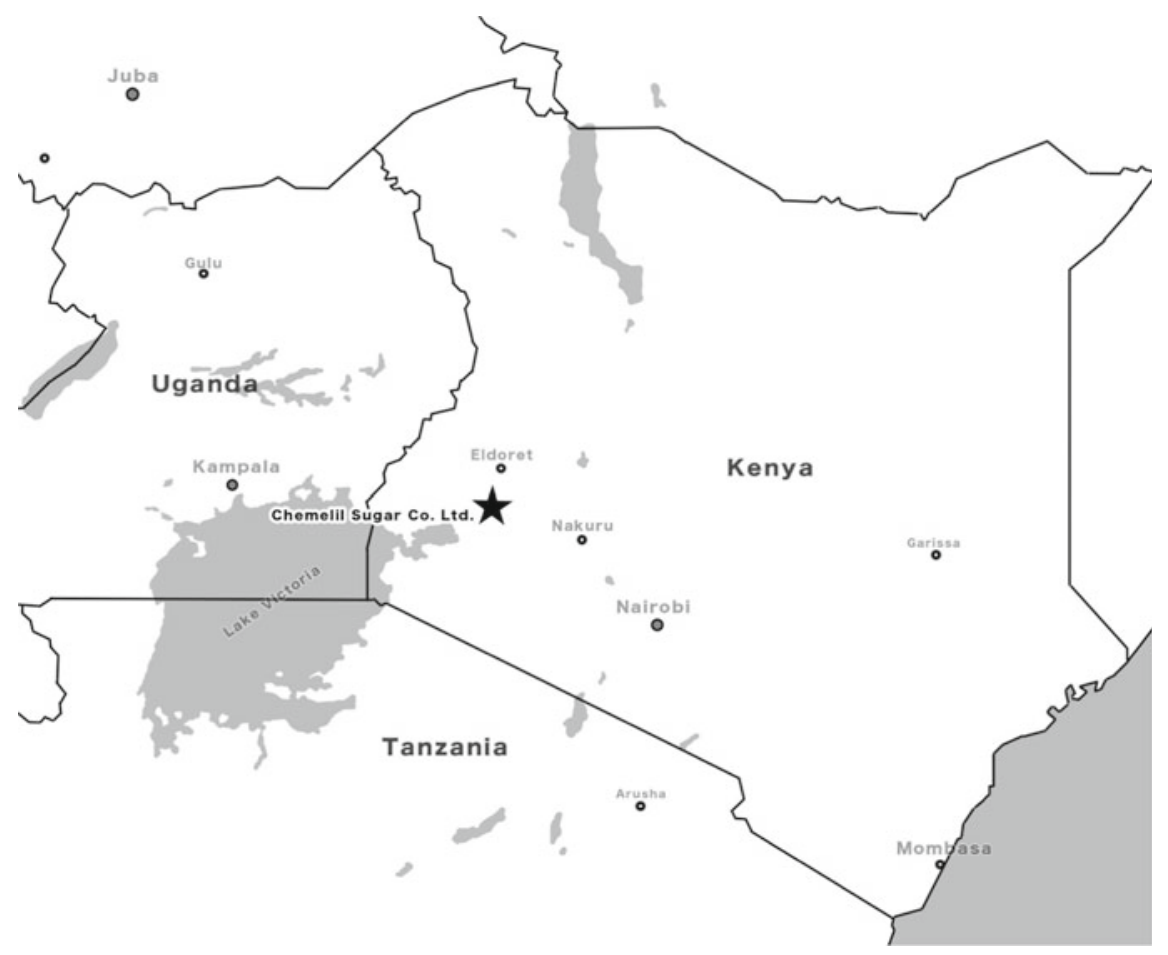

Fig. 1 Map of Kenya showing location of Chemelil Sugar Company Ltd.

afforded the opportunity to identify that farmers' access to cane millers were not significantly affected because of the growing competition for cane from neighbouring Kibos Sugar Company near Kisumu City and Muhoroni Sugar Company just a few kilometres away. Due to growing competition among cane millers in western Kenya, farmers have no incentive to stop producing cane using external technologies because external technologies provide the required cane harvest for competing companies. Thus, the politics of control over farmers is sustained by the companies through not only the market they offer but also the technologies they provide farmers to grow their cane. With regard to land reform, farmers' benefits from land through certainty of rights to land that seeks to motivate agricultural investment are unattained if the inputs and processes to harness land are beyond the control of farmers. Thus, the political ecology analytical framework suits the interpretation of the field data. This framework is presented after the methods section.

In our study area, farmers owned their lands, which were registered with the zonal land registry. Only a few farmers have leased lands that they have rented from their neighbours for two or three cane growing seasons. Land lease in Chemelil (for sugarcane production) is often quite expensive, and the terms are most often unfavourable to the tenant; for instance, the tenant farmer has to leave the land after two or three harvests. Subsequent shoots of cane, which can develop into a full-blown 
cane farm, becomes the property of the original landowner, not the lessee. Thus, only a few farmers can afford or are willing to rent land for this purpose.

Qualitative in-depth interactions and informal conversations were conducted among 40 farmers, 25 of whom were small-scale farmers cultivating between two and ten acres of land, ten were medium-scale farmers cultivating between 11 and 150 acres of land, and five were large-scale farmers cultivating farms larger than 150 acres. The inclusion of all three farmer categories was for triangulation purposes to ensure that the views of all segments of farmers were obtained.

Interactions with all categories of farmers, small-, medium-, and large-scale, who were all outgrowers ${ }^{2}$ in the Chemelil sugar belt, were conducted within the operational zone or cane catchment zone of the Chemelil Sugar Company. This means that all the farmers interviewed were outgrowers and supplied their cane to the Chemelil Sugar Company. The sugarcane growing belt covers over 18,000 ha of land. ${ }^{3}$ It encompasses outgrower farms in Muhoroni, Nyando, Tinderet, south Nandi, and east Nandi. The belt is divided into four parts, each manned or supervised by one extension officer operating to assist farmers in each zone. The interviews were conducted in all four zones in the presence of field officers from the Chemelil Sugar Company. These officers provided language interpretation where necessary, along with a vehicle for mobility in the remote areas of the region. Thus, the time for travelling around each day offered opportunities for the author to interact extensively with the field officers of the company.

\section{Political Ecology Analytical Framework}

The relationship between humans and the natural environment is mediated by many factors. In political ecology, researchers are concerned with issues of power and control over environmental resources, and how these influence different groups of people to harness and manipulate these resources (Batterbury 2018). Political ecology in the context of this study, with regard to land reform, focuses on the integration of ecological, political, and sociological factors for understanding the outcomes of land reform and agricultural development for farmers and other stakeholders. Such integrated understanding is even more complex when the influence of corporate entities in relation to environmental resources is large and deep (Adams 2017). The Chemelil case exhibits this complexity; the state agencies, such as the Kenya Agriculture and Livestock Organisation (KALRO), ${ }^{4}$ the Chemelil Sugarcane Company, and

\footnotetext{
${ }^{2}$ An outgrower is a farmer who is connected to input and extension service supplies from Chemelil Sugar Company but does not farm within the sugarcane fields (nucleus farms) owned by the company.

${ }^{3}$ Chemelil Sugar Company Brief. Company Head Office (obtained in October 2020).

${ }^{4}$ KALRO (www.kalro.org/ ) is a corporate body in Kenya focused on coordinating, regulating, and disseminating research in crops, livestock, genetic resources, and biotechnology.
} 
farmers co-produce and provide a rich context for understanding land and agricultural discourses.

The framework of political ecology applied on the discourse of land, as analysed through practices of intensive sugarcane production, indicates that smallholder farmers' control over their lands and innovations have been weakened by the power of knowledge over external agricultural technology wielded by external agents in the sugarcane industry, such as the Chemelil Sugar Company and KALRO. This political control over farmers has implications on the local agricultural infrastructure development and benefit to farmers. In the context of land and agriculture, political ecology suggests that it is important to view manifestations of systems of land administration and management as well as agricultural development, not as isolated events, but as processes controlled by political factors within the local agroeconomy (Clay 2018). Thus, the process of land use and how conceptions and incidence of power mediate these land uses, and their outcomes are relevant for understanding rural transformations through agriculture. Culture, politics, and social conditions are key elements of political ecology. How these conditions mediate the way a group of people relates and responds to land and agricultural policies and programmes plays an important role in understanding land discourses (Minch 2011; Bryant 2015).

In Chemelil, a political ecological understanding of land and power in land reform and intensive sugarcane production enables us to identify that, for agricultural productivity, sociological and political factors are as important as technology. The cane cultivation process in Chemelil captures how power over land transfers from farmers to state agencies and sugar companies, which helps understand land discourses and their major impact. In addition, we find that land tenure security is not the only factor that helps farmers to benefit from land titling. Power over land production inputs is equally relevant. The political ecology applied in Chemelil shows that beyond tenure reforms are issues of how power in and over land is generated and used to control benefits. In effect, ownership of knowledge of technologies and infrastructure, with attendant inherent power, is crucial for a wider conception of land reform for agricultural development. Local responses to power in the harnessing of land are also an important focus of political ecology (Bassett and Peimer 2015).

\section{Land Discourse in Kenyan National Land Policies}

\subsection{Land Reform for Agricultural Productivity}

Kenya enacted its latest land reforms in 2012. Key laws that culminated from the land reform process include the Land Act (No. 6 of 2012), Land Registration Act (No 3 of 2012), and National Land Commission Act (No. 5 of 2012). Other significant laws on land that were enacted prior to or with the land law reform include the National Land Policy in 2009 and the 2010 Constitution of Kenya, in which land policy is significantly highlighted in Chap. 5 'Land and Environment'. The reform, 
among other things, was aimed at ensuring equitable access to land and the security of rights in land through the registration of titles (Manji, 2014). It also sought to directly link land tenure security and equity with the promotion of agricultural productivity.

Historically, land reform in Kenya from the colonial era to the latest reform in 2012 has been premised on the 'efficiency and productivity' theory, particularly with regards to its intended positive outcome for agriculture (World Bank 1975). For instance, the 1954 land tenure reform in Kenya was formulated on the marketled approach of codifying individual freehold titles that were expected to revolutionise agricultural production through increased security of rights to motivate investments in land (Barber 1970). Thus, in the colonial period, land tenure reform aimed to uplift rural areas through increased agricultural productivity from a restrictive customary land tenure to a productive base of the economy. To this extent, the reform was primarily driven by agricultural officers to maintain a close link with agricultural production (Barber 1970). Being the first land reform (specifically land tenure reform), land titles were registered after land adjudication and consolidation (Coldham 1979).

In Kenya, the view that stronger user rights to land are likely to enhance investment and thereby land productivity, drives the intention of land titling to secure rights, investments in agricultural land, and land use efficiency. Land reforms in the context of agricultural production in Kenya are, therefore, an institutional reformation process towards enhanced productivity of land by encouraging investments of all sorts, including technological, financial, and human labour. In the previous Kenya land reform programmes, a Western market-led institutional model was the basis for the adjudication and registration of land rights. The model promoted private land titles (mostly individual but there were also a few communally owned titles) based on the values of the state in the land to increase agricultural productivity through external input supply to harness land that has clear ownership and titles. The drafters of the land reform laws believed that registered titles would grant clarity to ownership, full control, and security over land. Overall, land markets in Kenya are expected to induce efficiency in harnessing agricultural land, although equitable rights are also central yet less achieved (Kijima and Tabetando 2020). The case in Kenya reflects a general trend across eastern and southern Africa, where the means of land reform are often designed in ideological dualities yet combined in one reform. These dualities frame land reform in a continuum; at one end is land redistribution, sometimes associated with the state and equity goals (Logan et al. 2012) and, at the other end, there is market-led reform, which is often linked to efficient agricultural production (Logan et al. 2012).

Not much equity has been attained in Kenya's current land reforms (Manji 2014). Corrupt officials, hasty processes, and a lack of participation of most Kenyans in rural areas have hindered the achievement of equity with respect to access to the land addressed by the reforms. Nonetheless, the fieldwork for this chapter shows that land titling, which has been devolved to the county and sub-county levels, has contributed to securing the land rights for farmers and to the further development of agricultural intensification (in this context, intensive sugarcane production). However, the fieldwork also revealed that, despite farmers holding titles to their lands and, thus, 
enjoying secure rights in lands, most of these farmers are far removed politically from their lands. They hardly control any processes that go into the production of cane, except to refuse to plant for a particular season. For instance, in Chemelil, farmers plant cane ideally after the Chemelil Sugar Company has tested and certified the kind of cane to grow. Farmers also apply weedicides and chemicals recommended by the Chemelil Sugar Company to maintain a high yield and sucrose content of the cane. Thus, farmers who do not follow the recommendations risk producing cane that could be rejected at the factory. To this end, land reforms and their complementary agricultural efficiency are largely isolated from farmers' own innovative inputs in cane development and land conservation, which could give them more control over agricultural productivity benefits. The market-led productivity approach for land reform certainly provides immense benefits to the security of tenure that promotes investments in land. However, the realisation of these advantages depends on the context, that is, how the land law fits with existing local conditions.

Neo-liberal land reforms in Africa have ignored (in the context of this work, also created) local conditions and narratives over land. This has stifled agricultural productivity and exacerbated poverty (Logan et al. 2012). Logan et al. (2012) called for local narratives to be at the centre of land reform designs. The critique of the market-led approach for land reform is to find ideas that can complement the existing ones. These new ideas centrally include local discourse over land. In this study, the suggestion is that the basis and reasons for land reform should be broadened from the viewpoint of efficiency and productivity to acknowledge the political conditions that develop and affect farmers to innovate so as to benefit from agricultural productivity and sustained land. With respect to Tanzania, Boone and Nyeme (2015) show that local contexts strongly affect land tenure regimes.

Other concerns have been raised about the transformational outcome of the Kenya land reform programme, all of which point to the relevance of broadening the theoretical scope of land reform across all levels of society. Although the registration of titles has been successful, its success in economic and ecological transformation is debatable. There has been an increase in the concentration of land in the hands of a political/economic elite and agencies, with consequent growing landlessness. In agriculture, the conviction has been that land titling and the associated security of rights in land will promote investments in land and, thus, enhance agricultural productivity. Notably, investments in agricultural productivity have been witnessed by the author. However, this author also observed, similar to Holden and Ghebru (2016), that land tenure security may be a necessary but insufficient condition for farmers to sustainably manage their lands and benefit from agricultural investments and productivity. Land reform in Kenya has unfortunately failed to remove land control from the hands of bureaucrats, technocrats, and lawyers who, with their political power, are able to access and control land for their selfish personal interests at the expense of larger societal benefits (Boone et al. 2018). In the context of this work, land reforms and agricultural productivity have also placed much political control over land in the hands of agribusinesses at the expense of farmers' innovation to sustain their lands and benefit sustainably from sugarcane production. In the next section, empirical data from the field address these issues in the context of Chemelil. 


\section{Results and Discussions}

\subsection{Farmers Control Over Sugarcane Production Processes}

In this section, empirical work in Chemelil shows how sugarcane farmers are tied to practices imposed on them by state research agencies and the Chemelil Sugar Company. These practices have become imperative, according to the state research agency KALRO and the Chemelil Sugar Company for efficient land use and maximum land productivity. Farmers believe this discourse. Thus, for agribusinesssupported intensive sugarcane cultivation, the same discourse applies as that observed in state-supported land reform, in which land is considered to be an environmental asset that must be harnessed efficiently through optimal mechanisms for maximum productivity. However, local conditions that may affect farmers' innovations have not been a central focus in this approach. For state-sponsored land reform, the efficiency and productivity discourse is maintained by land title registration that provides certainty of rights to land to stimulate efficient investments in high agricultural productivity. This discourse is not different for agribusiness. For agribusinesses, such as Chemelil Sugar Company, the discourse of land is that land is considered to be an environmental asset to be harnessed through maximum use of external inputs and pursuance of externally determined farm practices for obtaining high productivity.

Sugarcane production involves a series of defined activities and decisions from soil preparation to harvesting and sales. Land preparation is strictly defined by extension advice from Chemelil Sugar Company, and soil analysis is conducted by the company to ascertain the best fertiliser and cane type to fit the land. The application of weedicides, pesticides, ploughing, planting of legumes, maize, and harvesting are all defined by the field managers of the Chemelil Sugar Company. Over time, farmers have learned to follow some of these practices without the aid of the extension personnel. Farmers pay for all these inputs, such as soil testing, ploughing, weedicides, and fertilisers. These inputs, according to the discourse on productivity, are necessary to ensure maximum output from the land. These decisions are embedded with power, coming from state research agencies like the KALRO to farmers and through the extension services of the Chemelil Sugar Company. Just as the land reform programme of the state carries power for landowners through the state title registration machinery and generally have to be adhered to, state agencies and the Chemelil Sugar Factory are seen by farmers as credible sources of cane-based power. Such power affected by the inputs and practices of cane farming provides the basis for farmers' behaviour and benefits from their lands over time (Batterbury 2018).

The application of externally developed inputs and defined sets of activities towards high productivity of cane farms is not unusual for agricultural intensification systems. The core features of any intensive agricultural system include the application of capital inputs, such as chemical fertilisers, mechanical ploughing, official soil testing, and 'improved' seedlings (Loconto et al. 2020). These technologies and capital inputs, often developed inorganically, are expected to guide how much and what kind of yield can be produced from a given piece of land. Thus, they are 
sources of power for those who possess such knowledge. In Chemelil, farmers do not possess or have failed to possess such knowledge.

Whether in land reform or intensive sugarcane farming, the discourse of land being an environmental asset to be harnessed through the productivity principle remains the same for both the state and agribusinesses. Sugarcane farmers have become a central channel for the legitimisation of this discourse. However, for sugarcane farmers, this principle comes with extensive costs borne by them. Farmers indicated that they would find ways to reduce these costs if they were free from external pressure to produce according to certain standards, although this would mean reduced yield at certain periods. In summary, the productivity principle, though crucial for enabling maximum profit from sugarcane lands, does not make these lands only an environmental asset but also a source of power as capital to promote one's interests. This power currently resides in the state and agribusiness. However, for farmers, the management of land entails a host of decisions and behaviours beyond productivity alone; it includes intergenerational access to land and land as the basis of community sustenance, among others. All these utilities of land are being weakened by the farmers' lack of control in the cane production process.

During the fieldwork, the definition of farm size in Chemelil was found to be interpreted differently by the farmers and the Chemelil Sugar Company. However, generally, most cane farmers in Chemelil classify themselves as small-scale farmers (i.e. those who farm between two and ten acres of land; the majority of the farmers in Chemelil are small-scale farmers), medium-scale farmers (those who farm between 11 and 150 acres of land), or large-scale farmers (those who farm over 150 acres, and even several hundred acres). In terms of efficiency and maximum productivity of land, all these categories of farmers pay for all the sets of activities, which is recurrent every growing season (ratoon), ${ }^{5}$ to grow cane to maturity; the only exceptions are the costs of soil testing and land preparation, which are not necessary after the first ratoon. Generally, these activities are more expensive in the first ratoon, where much more preparation of the land is required than in the second, third, and subsequent ratoons. For small-scale farmers, who are in the majority, paying for all these activities always involves high expenditure. Medium- and large-scale farmers enjoy economies of scale. In these decisions, farmers, especially small-scale ones, have little leverage to experiment with any form of practice to reduce their expenditures.

\subsection{Control Over Land and Local Infrastructure}

The deep influence exerted by the power inherent in external agents' supposed superior knowledge on farm practices and their technologies poses consequences that interfere with events that benefit farmers (Adam 2017). A consequence of the practice of Chemelil farmers maintaining their cane farms exclusively according

\footnotetext{
${ }^{5}$ Ratoon is the complete cycle of cane growth till harvest. It spans a period of about 15-18 months, depending on the cane type and discretion of the farmer.
} 
to external formal scientific advice is that there is little focus on local innovations towards performing operations in a different but less expensive manner. Throughout the season, farmers apply a list of fertilisers, such as ammonia and NPK, and weedicides, such as Sencor plus, on their farms in the name of efficiency of land production for high productivity. For every ratoon of cane growth, the cost of the application of inorganic fertilisers, weedicide, ploughing, and harvesting is borne heavily by the farmers, especially on the small-scale farmers. However, owing to high competition from the increasing number of sugarcane processing companies, farmers are interested in cultivating cane this way more than experimenting with new ideas from their experiences. Primarily, this is because they are not sure of the cane yield from their innovations. To this extent, they are unable to wean themselves from their high dependence on external technologies. The Chemelil Sugar Company currently competes with the Muhoroni Sugar Company and Kibos Sugar Company for cane from farmers.

A clear instance of power stifling local innovation in Chemelil is revealed in the farmers' attitudes towards beans. Farmers interplant cane with beans during the early growth period of the cane. However, interactions with farmers suggest that they do not actively invest time in institutionalised learning and are not innovating based on their everyday farming experiences. They know that beans, as legumes, are useful for soil nutrient enrichment. Further, the farmers acknowledged that they are not convinced that legumes can reduce the application of chemical fertilisers. Therefore, all farmers, whether they grow beans or not, still apply the same amount of inorganic fertiliser to enable yield as usual. When the beans are harvested, the herbage is sprayed with a weedicide to facilitate the growth of cane. Thus, farmers grow beans mainly for household consumption and not so much for the nitrogen fertilisation effect on the soil. Moreover, the cane brans left behind after harvesting the cane are burnt to clear the land for new planting, rather than being used as mulch or compost.

The external influence on cane production and land productivity discourse has the effect of stifling the development of farmer innovations to produce from but conserve their lands and maintain control over them for generations. Farmer innovations and infrastructure to promote productivity in this context could be locally designed agro-forestry systems, with plants that have value for farmers, composting systems that can make use of the large amount of cattle droppings and sugarcane brans left after harvest, and farmer cooperatives to negotiate for improved farming conditions. Although dependence on external inputs, such as advice and expertise from KALRO and the Chemelil Sugar Company, ensures adherence to cane development standards and, thus, guarantees income for farmers now, the effect is that farmers are already limited by the developments in the cane industry, which has been rather market-focused than farm-transformation focused. 


\subsection{Dependence on External Inputs and Youth Access to Land}

The efficiency and productivity goals, on which land reform and intensive agriculture are based, provide the older generation of people certainty of rights to land. However, this certainty of rights and attendant heavy agricultural investments pose counter challenges to the younger generation's access to land. The certainty of rights to land coupled with the lack of development of farm-level innovation and infrastructure for land production means that the cost of farming in Chemelil is high and beyond the means of many young people. In Chemelil, sugarcane production is an occupation for the older generation and not for the youth. The consequence is that land transfer to outsiders is increasing because the younger generation is discouraged from farming cane and is, thus, migrating to urban centres. The reasons are high investment expenditure in cane farming or lack of interest in cane production after their parents retire. During the field research, out of the 40 farmers who participated in this research, only two were below the age of 32 years and were involved in cane farming. One was a manager for an Indian family owning more than a thousand-acre cane farm, whereas the other was a cane farmer on his own land. These two farmers believe that the cane farming industry may not be sustainable in the near future because it does not have many young people for the two main reasons already mentioned, that is: (1) the heavy use of external inputs and technologies means expenditure is high-the youth find it better to leave for urban areas to find jobs than to work in cane farms; and (2) the inheritance system in rural areas is such that parents grow old and retire from farming before they hand over the land to their children. Consequently, many young potential cane farmers who have inherited cane farmlands from their parents are in urban areas and use labourers to manage their lands with possibility of mismanagement. These challenges weaken the value of land as a social and political asset at the community level. This problem was acknowledged by almost every farmer in this study.

The contention in this study is not against agricultural intensification. Intensification is an important approach to tackling poverty and redundancy in agriculture. This study agrees with Clay (2018) that constructing large-scale state development interventions, such as land reform and agricultural intensification, solely as inhibiting locally grounded agricultural strategies, masks the complexities of agrarian change and does not make way for understanding the nuanced methods in which local agencies interact with, overlap, and intersect external interventions to produce hybridities that are important to rural transformation (Clay 2018). From a Rwandese experience, Clay (2018) observes that large-scale state-supported intensification as development intervention has existed alongside small-scale innovations by smallholder farmers. In Chemelil, however, the power in the external direction for cane cultivation has tied farmers to unsustainable cane development paths (Waswa et al. 2012). This is why farmers did not pursue any major local innovations, at least not during the period of field research for this study. 


\section{Conclusions}

State-sponsored land reform and the Chemelil Sugar Company share the same discourse on land, where land is an environmental asset to be managed and harnessed efficiently for high productivity through agricultural intensification. In this study, this land discourse has been analysed as creating a linkage between state-supported land reform, agribusinesses, and farmers in the context of intensive sugarcane production in Chemelil. However, this discourse underlies and brings together land reform and sugarcane production into a strong force that impedes farmers' control over their lands. The discourse on land with both the state land reform and agribusiness is that land is a material asset for which ownership is to be secured through titling. Land is also useful for its natural resources of soil and nutrients for agricultural productivity. In a political ecology sense, this process of pursuing efficiency and productivity, from land titling to agribusiness intensive sugarcane production, while not inappropriate in itself, has acquired the status of a political mechanism that imposes agricultural inputs on farmers, with high financial costs. As farmers are incorporated deeply into sugarcane production through readily supplied inputs, their innovative capacities to reduce the costs of farming for sustainable benefits from their lands have not been harnessed.

The social and political consequences of pursuing efficiency and productivity in harnessing land without considering the context of farmers are that the place of land in the social organisation of the household has been eroded. The erosion occurs because land is held by the older generation without the assured continuity of farming by younger people. Household land transfers to outsiders that reduce household land property are also rising as a result of many people preferring to lease inherited land or sell it off to outsiders. The problem is worsened by land fragmentation through inheritance, which reduces the possibilities for efficient use of land. The solutions for these issues cannot be professed at this stage in this study. Rather, the current study opens opportunities for further research on ways to complement current ideas of land reform and agricultural productivity that can ensure farmers' equitable control over their lands. The study also provides exploratory insights for research into the consolidation of land for farming households.

\section{References}

Adams, W.M. 2017. Sleeping with the enemy? Biodiversity conservation, corporations and the green economy. Journal of Political Ecology 24 (1): 243-257.

Barber, W.J. 1970. Land reform and economic change among African farmers in Kenya. Economic Development and Cultural Change 19 (1): 6-24.

Bassett, T.J., and A.W. Peimer. 2015. Political ecological perspectives on socio ecological relations. Natures Sciences Sociétés 23 (2): 157-165.

Batterbury, S.P.J. 2018. Political ecology. In The companion to environmental studies, ed. N. Castree, M. Hulme, and J. Proctor, 439-442. London: Routledge. 
Boone, C. 2019. Legal empowerment of the poor through property rights reform: Tensions and trade-offs of land registration and titling in sub-Saharan Africa. The Journal of Development Studies 55 (3): 384-400.

Boone, C., and L. Nyeme. 2015. Land institutions and political ethnicity in Africa: Evidence from Tanzania. Comparative Politics 48 (1): 67-86.

Boone, C., A. Dyzenhaus, A. Manji, C.W. Gateri, S. Ouma, J.K. Owino, A. Gargule, and J.M. Klopp. 2018. Land law reform in Kenya: Devolution, veto players, and the limits of an institutional fix. African Affairs 118 (471): 215-237. https://doi.org/10.1093/afraf/ady053.

Bryant, R., ed. 2015. The International handbook of political ecology. Cheltenham: E. Elgar.

Clay, N. 2018. Seeking justice in green revolutions: Synergies and trade-offs between large-scale and smallholder agricultural intensification in Rwanda. Geoforum 97: 352-362.

Coldham, S.F.R. 1979. Land-tenure reform in Kenya: The Limits of law. The Journal of Modern African Studies 17 (4): 615-627.

Fuglie, K.O. and N.E. Rada. 2013. Resources, policies, and agricultural productivity in Sub-Saharan Africa. SSRN Electronic Journal. US Department of Agriculture, Economic Research Service: ERR-145.

Gollin, D., D. Lagakos, and M.E. Waugh. 2014. Agricultural productivity differences across countries. American Economic Review 104 (5): 165-170. https://doi.org/10.1257/aer.104.5.165.

Gottlieb, C., and J. Grobovšek. 2019. Communal land and agricultural productivity. Journal of Development Economics 138: 135-152.

Holden, S.T., and H. Ghebru. 2016. Land tenure reforms, tenure security and food security in poor agrarian economies: Causal linkages and research gaps. Global Food Security 10: 21-28.

Kijima, Y., and R. Tabetando. 2020. Efficiency and equity of rural land markets and the impact on income: Evidence in Kenya and Uganda from 2003 to 2015. Land Use Policy 91: 1-13.

Lipton, M. 2009. Land reform in developing countries: Property rights and property wrongs. Abingdon: Routledge.

Loconto, A., M. Desquilbet, T. Moreau, D. Couvet, and B. Dorin. 2020. The land sparing-land sharing controversy: Tracing the politics of knowledge. Land Use Policy 96: 103610. https://doi. org/10.1016/j.landusepol.2018.09.014.

Logan, B.I., G. Tengbeh, and B. Petja. 2012. Towards a reorientation in land reform: From a market to locality-driven approach in South Africa's land restitution programme. Progress in Development Studies 12 (2-3): 173-191. https://doi.org/10.1177/146499341101200306.

Manji, A. 2006. The politics of land reform in Africa: From communal tenure to free markets. London: Zed Books.

Manji, A. 2014. The politics of land reform in Kenya 2012. African Studies Review 57 (1): 115-130.

Minch, M. 2011. Political ecology. In Encyclopedia of global justice, ed. D.K. Chatterjee. Dordrecht: Springer. https://doi.org/10.1007/978-1-4020-9160-5_119.

Narh, P., C.K. Lambini, M. Sabbi, V.D. Pham, and T.T. Nguyen. 2015. Land sector reforms in Ghana, Kenya and Vietnam: A comparative analysis of their effectiveness. Land 5 (2): 1-17.

Netshipale, A.J., S.J. Oosting, M.L. Mashiloane, C.G. Van Reenen, I.J.M. de Boer, and E.N. Raidimi. 2020. Agriculture in land reform farms: Impact on livelihoods of beneficiaries in the Waterberg district, South Africa. Land Use Policy 97. https://doi.org/10.1016/j.landusepol.2020.104710

Obeng-Odoom, F. 2012. Land reforms in Africa: Theory, practice, and outcome. Habitat International 36 (1): 161-170.

Place, F. 2009. Land tenure and agricultural productivity in Africa: A comparative analysis of the economics literature and recent policy strategies and reforms. World Development 37 (8): 1326-1336. https://doi.org/10.1016/j.worlddev.2008.08.020.

Tenaw, S., K.M.Z. Islam, and T. Parviainen. 2009. Effects of land tenure and property rights on agricultural productivity in Ethiopia, Namibia and Bangladesh. Discussion papers No. nro 33. University of Helsinki, Department of Economics and Management. http://www.mm.helsinki.fi/ mmtal/abs/DP33.pdf.

Waswa, F., J.P. Gweyi-Onyango, and M. Mcharo. 2012. Contract sugarcane farming and farmers' incomes in the Lake Victoria basin, Kenya. Journal of Applied Biological Sciences 52: 3685-3695. 
World Bank. 1975. Land reform: Sector policy paper. Washington, DC.

Zikhali, P. 2008. Fast track land reform and agricultural productivity in Zimbabwe. Working Papers in Economics No 322. School of Business, Economics and Law, University of Gothenburg.

Open Access This chapter is licensed under the terms of the Creative Commons Attribution 4.0 International License (http://creativecommons.org/licenses/by/4.0/), which permits use, sharing, adaptation, distribution and reproduction in any medium or format, as long as you give appropriate credit to the original author(s) and the source, provide a link to the Creative Commons license and indicate if changes were made.

The images or other third party material in this chapter are included in the chapter's Creative Commons license, unless indicated otherwise in a credit line to the material. If material is not included in the chapter's Creative Commons license and your intended use is not permitted by statutory regulation or exceeds the permitted use, you will need to obtain permission directly from the copyright holder.

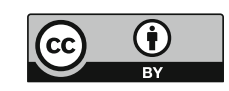

